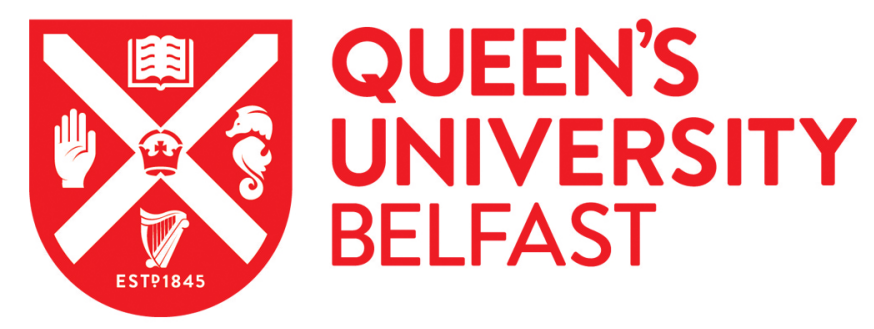

\title{
Nurses' experiences of pain management for people with advanced dementia approaching the end of life: a qualitative study
}

De Witt Jansen, B., Brazil, K., Passmore, P., Buchanan, H., Maxwell, D., Mcilfatrick, S. J., Morgan, S. M.,

Watson, M., \& Parsons, C. (2017). Nurses' experiences of pain management for people with advanced dementia approaching the end of life: a qualitative study. Journal of Clinical Nursing, 26(9-10), 1234-1244.

https://doi.org/10.1111/jocn.13442

Published in:

Journal of Clinical Nursing

Document Version:

Peer reviewed version

Queen's University Belfast - Research Portal:

Link to publication record in Queen's University Belfast Research Portal

\begin{abstract}
Publisher rights
(C) 2016, Wiley

This is the peer reviewed version of the following article: De Witt Jansen, B, Brazil, K, Passmore, P, Buchanan, H, Maxwell, D, Mcilfatrick, SJ, Morgan, SM, Watson, M \& Parsons, C 2016, 'Nurses' experiences of pain management for people with advanced dementia approaching the end of life: a qualitative study' Journal of Clinical Nursing, which has been published in final form at

http://onlinelibrary.wiley.com/doi/10.1111/jocn.13442/abstract. This article may be used for non-commercial purposes in accordance with Wiley Terms and Conditions for Self-Archiving.

General rights

Copyright for the publications made accessible via the Queen's University Belfast Research Portal is retained by the author(s) and / or other copyright owners and it is a condition of accessing these publications that users recognise and abide by the legal requirements associated
\end{abstract} with these rights.

Take down policy

The Research Portal is Queen's institutional repository that provides access to Queen's research output. Every effort has been made to ensure that content in the Research Portal does not infringe any person's rights, or applicable UK laws. If you discover content in the Research Portal that you believe breaches copyright or violates any law, please contact openaccess@qub.ac.uk. 
Received Date : 18-Apr-2016

Accepted Date : 11-Jun-2016

Article type : Original Article

Nurses' experiences of pain management for people with advanced dementia approaching the end of life: a qualitative study

Pain management in dementia at end of life

Bannin DE WITT JANSEN BSc, MA, PhD Research Fellow, School of Pharmacy, Queen's University Belfast, United Kingdom

Kevin BRAZIL BA, MA, PhD Professor of Palliative Care, School of Nursing and Midwifery, Queen's University Belfast, United Kingdom

Peter PASSMORE MB BCh BAO, MRCP, MD Consultant Geriatrician and Professor of Ageing and

Geriatric Medicine, Centre for Public Health, School of Medicine, Dentistry and Biomedical Sciences, Queen's University Belfast, United Kingdom

Hilary BUCHANAN MB BCh BAO, DRCOG, MRCGP Retired General Practitioner, Patient and Public Involvement Representative, Carer for a person living with dementia

This article has been accepted for publication and undergone full scientific peer review but has not been through the copyediting, typesetting, pagination and proofreading process which may lead to differences between this version and the Version of Record. Please cite this article as an 'Accepted Article', doi: 10.1111/jocn.13442 This article is protected by copyright. All rights reserved. 
Doreen MAXWELL MB BCh BAO, DRCOG, MRCGP General Practitioner, Kerrsland Surgery, Belfast, United Kingdom

Sonja J. MCILFATRICK RGN, MSc, PhD Professor of Nursing, Institute of Nursing and Health Research Ulster University, United Kingdom. Senior Investigator, All Ireland Institute of Hospice and Palliative Care, Dublin, Ireland.

Sharon M. MORGAN MB BCh BAO, DRCOG, MRGCP General Practitioner, Marie Curie Hospice, Belfast, United Kingdom

Max WATSON MB BCh BAO, MPhil, MRCGP Professor in Palliative Care, Medical Director of the Northern Ireland Hospice, Belfast, United Kingdom

*Carole PARSONS MPharm, PhD, MPSNI Lecturer in Pharmacy Practice, School of Pharmacy, Queen's University Belfast, 97 Lisburn Road, Belfast, United Kingdom. Email: c.parsons@qub.ac.uk; Telephone: (0) 289097 2304; Fax: (0) 289024 7794. *Corresponding author.

\section{Acknowledgements}

The authors acknowledge and thank all research participants, participating hospices, nursing homes, secondary care units and local collaborators within the HSC Trusts who supported and facilitated this research

This article is protected by copyright. All rights reserved. 


\section{Declaration of conflicting interests}

Professor Peter Passmore has received funding (educational grants) from Napp, Grünenthal and Pfizer, and has spoken and/or chaired meetings for these companies. Napp, Grünenthal and Pfizer had no role in the development, analysis or reporting of the present study. The other authors have no conflicts of interest to declare.

\section{Funding statement}

This research was funded by a research grant awarded to Dr Carole Parsons by HSC Research and Development Division (HSC R\&D), Public Health Agency, Northern Ireland, in association with The Atlantic Philanthropies (COM/4885/13).

\section{Author contributions}

All authors meet the following authorship criteria:

- substantial contributions to conception and design of, acquisition of data or analysis and interpretation of data;

- drafting the article or revising it critically for important intellectual content;

- final approval of the version to be published.

\section{ABSTRACT}

Aims and objectives. To explore hospice, acute care and nursing home nurses' experiences of pain management for people with advanced dementia in the final month of life. To identify the challenges, facilitators and practice areas requiring further support.

This article is protected by copyright. All rights reserved. 
Background. Pain management in end-stage dementia is a fundamental aspect of end of life care; however, it is unclear what challenges and facilitators nurses experience in practice, whether these differ across care settings, and whether training needs to be tailored to the context of care.

Design. A qualitative study using semi-structured interviews and thematic analysis to examine data.

Methods. 24 registered nurses caring for people dying with advanced dementia were recruited from ten nursing homes, three hospices, and two acute hospitals across a region of the United Kingdom. Interviews were conducted between June 2014 and September 2015.

Results. Three core themes were identified: challenges administering analgesia, the nurse-physician relationship, and interactive learning and practice development. Patient-related challenges to pain management were universal across care settings; nurse- and organisation-related barriers differed between settings. A need for interactive learning and practice development, particularly in pharmacology, was identified.

Conclusions. Achieving pain management in practice was highly challenging. A number of barriers were identified; however, the manner and extent to which these impacted on nurses differed across hospice, nursing home and acute care settings. Needs-based training to support and promote practice development in pain management in end-stage dementia is required.

Relevance to clinical practice. Nurses considered pain management fundamental to end of life care provision; however, nurses working in acute care and nursing home settings may be undersupported and under-resourced to adequately manage pain in people dying with advanced dementia. Nurse-to-nurse mentoring and ongoing needs-assessed interactive case-based learning could help promote practice development in this area. Nurses require continuing professional development in pharmacology.

This article is protected by copyright. All rights reserved. 


\section{WHAT DOES THIS PAPER CONTRIBUTE TO THE WIDER GLOBAL COMMUNITY?}

- Globally, pain management in palliative care is a health policy priority; however, it is unclear what barriers and facilitators are experienced by nurses caring for people with advanced dementia in the final month of life and whether these differ across care settings.

- Patient-related barriers to pain management were universal across nurse participants and care settings. However, the barriers arising from nurse-related and organisational factors, and extent to which they impacted on nurses' experiences of pain management, varied across acute care, hospice and nursing home care settings.

- This study identified a gap between health policy recommendations for pain management in palliative care and availability of resources to support nurses working in different healthcare settings in implementing these recommendations in clinical practice.

KEYWORDS: pain, palliative care, dementia, nurse, nurse education

\section{INTRODUCTION}

Dementia has become a leading cause of disability and a significant contributor to mortality in developed countries propelling it to priority status in healthcare policy, research and education globally (World Health Organisation 2012, van der Steen et al. 2014). A recent study estimated that the prevalence of dementia worldwide has reached 46.8 million; a figure expected to reach 74.7 million by 2030 (Prince et al. 2015). The potential impact of the increasing global and local prevalence of dementia on healthcare services and staff, who will be managing this population to the end of life, requires consideration. The complex pattern of behavioural and cognitive deficits displayed in dementia results in a patient population whose care requirements differ from those in whom these abilities remain functional. Whilst models of palliative care may be extrapolated from

This article is protected by copyright. All rights reserved. 
one health context to another (e.g. the application of the palliative care model for cancer to other terminal conditions), they are often not appropriate for use in patients who are unable to participate in, comprehend or consent to, decisions regarding their own care (Rabins and Black 2007). Institutional settings, such as nursing and residential homes, hospitals and hospices, are commonly the last place of care for many older adults with dementia (Ahmad \& Mahoney 2005, Houttekier et al. 2010). Understanding the barriers to and facilitators of care experienced by healthcare professionals in these settings therefore becomes critical to identify areas where patient needs are not met and in the development of efficient and feasible strategies which adequately support staff in their practice.

Optimal palliative care for people with dementia, including the management of pain, has been highlighted as a priority in health policy globally (Department of Health 2009, van der Steen et al. 2014). However, evidence suggests suboptimal pain management in people with dementia compared to cognitively intact older people, including under-prescribing of analgesia for people with dementia in long-term care, in cancer, after hip fracture and in postoperative care (Bell 1997, Horgas \& Tsai 1998, Kaasalainen et al. 1998, Morrison \& Siu 2000, Nygaard \& Jarland 2005, Cornali et al. 2006, Reynolds et al. 2008, Monroe et al. 2013).

\section{BACKGROUND}

The prevalence of comorbidities in people with dementia often necessitates pain management throughout disease progression and into the final months of life (Mitchell et al. 2009, Klapwijk et al. 2014, Hendriks et al. 2015). The challenges of assessing and managing pain in this complex population have attracted sustained research attention, particularly with regards to the attitudes, knowledge and practices of nursing staff who play a significant role in pain assessment and management (Kovach et al. 2000, Nygaard \& Jarland 2005, Kaasalainen et al. 2007, Zwakhalen et al. 2007, Barry et al. 2012). Nurses' attitudinal beliefs towards, and knowledge of, the presence, experience and impact of pain on older adults with and without dementia, have critical implications

This article is protected by copyright. All rights reserved. 
for assessment and treatment, and have been linked to delayed assessment of pain, suboptimal treatment and underuse of pro re nata (PRN) analgesia (Kovach et al. 2000, Nygaard \& Jarland 2005, Kaasalainen et al. 2007, Zwakhalen et al. 2007, Barry et al. 2012).

A substantial body of compelling evidence has identified deficits in nurses' knowledge of pain assessment, pharmacology, side-effects and dosing schedules and the presence of misguided perceptions regarding the use of opioids and regularly prescribed analgesics, suggesting that nursing staff are inadequately educated on the use of analgesics in palliative care for people with dementia (Kovach et al. 2000, Auret \& Schug 2005, Barry et al. 2012, Ghandehari et al. 2013). Poor pain management has a number of adverse outcomes for patients including the manifestation or exacerbation of neuropsychiatric symptoms, agitation, depression, challenging and resistive behaviour and sleep disturbance (Cipher \& Clifford 2004, Hadjistavropoulos et al. 2007). Previous studies have focused on nurses' experience of pain management prior to the end of life but little is known about attitudes of and competence in pain management in the final weeks. A small qualitative study by Brörson and colleagues (2014) explored the experiences of nurses working in a Swedish hospital dedicated to the care of patients with neuropsychiatric disorders including dementia. Barriers to pain management identified included difficulties obtaining analgesic prescriptions, anxiety regarding use of morphine, and problems with nurse-physician communication (Brörson et al. 2014). To the knowledge of the authors, no studies have been conducted to date which explore nurses' experiences and perspectives of pain management for people with advanced dementia nearing the end of life across multiple care settings including hospice, acute care and nursing home contexts. This study aims to address this gap in the literature.

\section{AIM}

The aim of this research was to explore hospice, nursing home and acute care nurses' experiences of pain management, the perceived barriers to and facilitators of pain management, and perspectives on training needs in managing pain in people with advanced dementia in the final month of life.

This article is protected by copyright. All rights reserved. 


\section{METHOD}

\section{Design}

This qualitative study forms part of a larger programme of research aimed at exploring nurses', physicians' and healthcare assistants' experiences of pain assessment and management for people with advanced dementia in the final month of life with a view to developing a complex intervention to address clinical and professional issues identified, to improve pain assessment and management for this vulnerable patient group. This qualitative study used face-to-face, semi-structured interviews to explore nurses' experiences.

\section{Data collection}

Ethics

Ethical approval was granted by the Office for Research Ethics Committees Northern Ireland (ORECNI) (14/NI/0013). The study protocol and supporting materials were reviewed and approved by independent ethics committees in the participating hospices, in one large chain-owned nursing home and by the participating HSC Trusts.

\section{Sample and recruitment}

Registered nurses (RNs) with responsibility for caring for people with advanced dementia who were nearing the end of life and/or who had died were eligible for participation. We aimed to recruit a maximum variation sample (regarding age, job role, educational attainment and length of clinical experience) of nurses within hospice, acute care hospital and nursing home care settings. Index contacts in each of these settings were approached for participation in the first instance and subsequent participants were contacted through an onward process of nominative sampling.

This article is protected by copyright. All rights reserved. 
Nursing home managers and hospice medical directors distributed study materials to eligible participants within their respective care settings. In acute care, consultant physicians (in geriatric medicine, care of the elderly and palliative medicine) distributed study information, comprising an invitation cover letter and participant information sheet, to eligible nursing teams within their hospitals. All nurses who responded to the participation call were recruited into the study. Twentyfour nurses were recruited from three hospices, two acute care hospitals and ten nursing homes. These settings cover four out of the five regional Health and Social Care (HSC) Trust areas in Northern Ireland (NI), United Kingdom (UK). Recruitment ceased when no further novel data were identified in transcripts at the within-group and across-group levels and data saturation was achieved.

\section{Data collection tools}

Semi-structured, in-person interviews were conducted with nurses at their place of work. All participants provided written informed consent. An interview topic guide of open-ended questions was used; this was developed from a review of the literature and refined to suit the focus of the study. Interview topics covered: experiences of managing pain in people dying with advanced dementia, barriers to and facilitators of, pain management, and training needs. All interviews were digitally audio-recorded and transcribed verbatim. Interview duration ranged from 31 minutes to 45 minutes (average 37.9 minutes). Shorter duration interviews reflect the challenges of interviewing hospital nurses. Data were collected between June 2014 and September 2015.

\section{Data analysis}

Data management and analysis were facilitated using NVivo10 software (QSR International (UK) Ltd, Cheshire, UK). Thematic analysis using Braun and Clarke's (2006) paradigm was the analytical approach taken to data analysis. Following several re-readings of each transcript, passages of text comprising feelings, thoughts, short narratives, perspectives and experiences were assigned

This article is protected by copyright. All rights reserved. 
descriptive codes reflecting the concepts expressed by those data. To ensure consistency, coding was performed in constant comparison to coding completed in prior transcripts and a coding frame was developed. Codes were reviewed and grouped by concept (e.g. 'route of administration') and then arranged by theme (e.g. 'challenges administering analgesia'). To identify whether differences in nurses' experiences of pain management were differentially impacted by the care setting in which they practised, analysis was performed at two levels. In the first instance, data were analysed at the level of the care-setting for each group (hospice nurses, acute care nurses and nursing home nurses) and subsequently expanded to cross-group comparison (hospice versus acute care versus nursing home).

\section{Validity and reliability/Rigour}

Recommendations from established and recent literature on demonstrating validity, reliability and rigour in qualitative research were adopted and employed throughout this study (Rolfe 2006). All interviews were transcribed verbatim by the research fellow (Initials); these were checked for accuracy against the original digital recordings by two members [Initials of academic professor 1] and [initials of Patient and Participant Involvement Representative] of the Project Management Group (PMG). Primary data analysis was performed by the research fellow, after which a selection of transcripts were independently analysed by [initials of Principal Investigator] and [initials of academic professor 1]. The process of data analysis and identification of the core themes were discussed and agreed between the three authors and presented to and discussed in bi-monthly meetings of the PMG; a group comprising two practising academic-physicians in geriatric/dementia and palliative care, four academics specialising in palliative care, nursing and palliative care and pharmacy, three General Practitioners (GPs) with a special interest in older adults, dementia and palliative care, and one Patient and Public Involvement representative (also a retired GP). An audit trail of the analysis was kept, detailing steps in the development of the coding frame and each level of analysis.

This article is protected by copyright. All rights reserved. 


\section{RESULTS}

A total of 24 participants comprising hospice nurses $(n=6)$, acute care nurses $(n=6)$ and nursing home nurses $(n=12)$ were recruited. The majority were female $(n=23)$. Participants had an average age of 36.8 years (range: 25 to 59 years) and an average of 13.8 years' nursing experience (range: 3 months to 34 years). Seven participants had postgraduate qualifications including a diploma or master's degree in palliative care, and one participant was undertaking the first year of doctoral study in palliative nursing at the time of the study. Nurse grades ranged from staff nurse to nurse manager. Participant characteristics are presented in full in Table 1.

Table 1. Participant characteristics

Participants' experiences were characterised into three core themes: (1) challenges administering analgesia, (2) the nurse-physician relationship and (3) interactive learning and practice development. The theme "challenges administering analgesia" reflects challenges arising from the inherent complexity of the patient population (people dying with advanced dementia) and as such, nurses' experiences were universal and not differentially impacted by setting. The second and third core themes comprised both commonalities of experience across settings, with sub-themes reflecting setting-specific challenges. In these cases, experiences were common to nurses within a specific care setting (e.g. acute care) but differed from experiences of nurses in other settings (e.g. hospice). Core themes and sub-themes are presented in Table 2.

Table 2. Core themes and sub-themes identified in within-group and cross-group analysis

\section{Challenges administering analgesia}

Commonly experienced challenges with the administration of analgesia comprised patient refusal of pain relief and difficulties with routes through which analgesics could be administered.

This article is protected by copyright. All rights reserved. 


\section{Medication refusal}

Patient refusal of analgesia (and other medications) was commonly experienced by participants with most perceiving refusal as the result of patient anxiety and/or fear regarding medication use. It was believed that profound deficits in cognition prevented patients from recognising medications as such, and impairments in communication removed the possibility of engaging in nurse-patient dialogue to explain the need for, and benefits of, analgesia, through which patients' fears and anxieties might be allayed.

It can be difficult then to explain that this is what is working for you and we think that this will help you". (NURSO22 - Hospice nurse)

In some cases, patients' inability to understand the purpose of pain relief provided, combined with the pain they were experiencing, culminated in aggressive resistance to treatment.

Some of them would be aggressive, they will just full stop not take any pain relief from you and yet you know they need the pain relief. (NURSO2 - Nursing home nurse)

Many nurses expressed deep empathy for patients, reflecting that fear and/or anxiety were natural responses in dying patients who are entirely dependent on others for care and who cannot understand or adequately express their needs.

Put yourself in the shoes of the resident, you're lying there, you can't talk, you can't understand. You're really at the mercy of the people looking after you. (NURSO16 - Nursing home nurse)

Route of administration

Participants reported barriers to pain management in patients dying with advanced dementia resulting from constraints on available and appropriate routes of administration. Oral administration of analgesia was challenging in dying patients with frequent and/or excessive drowsiness or who

This article is protected by copyright. All rights reserved. 
were asleep for extended periods of time. Analgesic use in tablet and liquid formulations carried a high risk of aspiration pneumonia for patients with dysphagia, a common feature in end-stage dementia, often necessitating a review of patients' analgesic regimens.

The challenge is they can't take it orally a lot of the time because their swallow deteriorates and they frequently get aspiration pneumonia so whatever oral pain relief they would have been on previously, they can't take anymore. (NURS09 - Acute care nurse)

Participants reported that syringe drivers, injections and intravenous administration could be challenging when used for end-stage patients with dementia with low body fat, little musculature and cachexia.

People with advanced dementia tend to have skin and bones as they haven't been eating great so even like giving subcut [subcutaneous] injections or intramuscular sometimes there's nowhere to put it that's not going to cause more pain whenever you're administering it. (NURS020 - Acute care nurse)

Many expressed concern regarding the use of needles in dying patients due to beliefs that these routes were painful and distressing for patients, especially for those who were already anxious and/or agitated.

...they can become more anxious coming near the end...if they see a needle they're freaked out so you have to assess the situation, is it really worthwhile me putting such and such through this here? (NURSO6 - Hospice nurse)

Respondents preferred less invasive methods such as suppositories and transdermal patches over subcutaneous and intravenous delivery in the final weeks of life and for the imminently dying; these were considered to be minimally invasive with low risk of injury to patients during administration.

This article is protected by copyright. All rights reserved. 
We start with a patch of some description for pain relief, so that keeps them pain free. I find that for people who have dementia, you don't tend to need syringe pumps, you'd use paracetamol suppositories, maybe diazepam suppositories. (NURS09 -Acute care nurse)

\section{The nurse-physician relationship}

\section{Positive relationships}

All hospice nurses reported positive nurse-physician relationships which were characterised by mutual professional respect, trust and collaboration. They perceived themselves to be working in successful partnership with medical staff towards a common goal of pain management.

I think we're doing quite well [in managing pain], but I think it is because we have such a good, you know, we have a good team and we have specialists, you know, as well, I think that all ties in together. (NURSO17 - Hospice nurse)

Just over half of nursing home nurses and acute care nurses also reported positive nurse-physician relationships. These nurses perceived that physicians responded promptly to reports of pain and to prescription requests, demonstrated shared goals of care, and valued nurses' contribution to patient care. Open and articulate communication facilitated a collaborative relationship between nurses and physicians in which disciplinary knowledge was shared to meet the challenges of managing pain as well as other aspects of patient care.

The GPs are there all the time to help, they always go with us because they know that we are the ones seeing [the patients] everyday, we know each and every difference in them from yesterday, today, tomorrow. So when we explain, they have trust in us. (NURS013 Nursing home nurse)

This article is protected by copyright. All rights reserved. 


\section{Difficult relationships}

Difficult nurse-physician relationships were reported by both nursing home and acute care nurses.

Some nurses felt that physicians were reluctant to conduct patient assessments and ignored requests for help with complex cases.

Some will say: well, what's wrong with them? And try and diagnose over the phone, rather than actually coming out and doing a home visit. Probably one of the biggest issues that we have, is that the GPs wouldn't always come out and help us assess. (NURS015 - Nursing home nurse)

Negative relationships were also reported where participants experienced difficulties or delays in obtaining scripts, where prescribing decisions were perceived (and/or transpired) to be subtherapeutic, and where treatment appeared to be unreflective of patient needs.

Sometimes I think there's reluctance on the part of the medical [staff], especially if it's a junior medic, you know, to even prescribe something. (NURS021 - Acute care nurse)

Senior acute care and nursing home nurses felt confident in advocating for patients in cases where nurses' and physicians' goals of care were perceived to be discordant but acknowledged that confidence to query prescribing decisions varied among nurses.

Some [GPs] have their own thoughts and trends in their head and what they believe is right. I think they open a book and it says A, B, C and D to them and therefore they want to follow A, B, C and D to do their best, but sometimes they forget to listen to the nurses who do know. I think it depends on how empowered a nurse is to actually say to a GP: hold on a minute, and to be an advocate for our residents. (NURSO3 - Nursing home nurse manager)

This article is protected by copyright. All rights reserved. 
Nurses with 20 or more years' nursing experience believed that poor communication skills and inadequate reporting among nursing staff contributed to the difficulties experienced in nursephysician relationships. Failure to provide salient, contextual information about patients (such as changes in swallow) clouded the clinical picture for physicians, especially for those not present in the care setting daily, in some cases resulting in clinical errors and/or inappropriate treatment.

If it's a GP writing up, their initial thing would be to write up the ordinary capsules but it's the nurses being proactive to say, whenever they're getting it prescribed: “Oh this patient's swallow is quite impaired, is there any other form that can be given in?" So it's not the GP's fault, it's the nurses not informing them of the actual situation. (NURS010 - Nursing home nurse)

\section{Interactive learning and practice development}

\section{Hospice nurses}

Hospice nurses perceived themselves to be fortunate in being able to readily access ongoing professional development across many aspects of dementia care including pain management.

I think we are quite lucky here because we get quite a lot of training [...]. You're getting your practical training, you have your mentor, and you learn so much from your mentor. And then we have online training and we have certain study days dedicated to it [dementia] and if we want we can get external training as well. (NURS05 Hospice nurse).

Hospice nurses expressed preference for interactive, group discussion of patient cases alongside structured didactic teaching, reporting that these approaches facilitated and encouraged knowledge exchange between nursing staff.

This article is protected by copyright. All rights reserved. 
Usually here we would have small groups $[. .$.$] and it's very interactive and it's not very formal$ but it's very, very, informative, very good. And then you can bounce ideas off each other, it's very good I think. (NURSO11 - Hospice nurse)

Acute care and nursing home nurses

These nurses' experiences of training and development differed substantially to those of hospice nurses. Opportunities for professional and practice development were often limited for acute care and nursing home nurses due to constraints on staff time, heavy workload and the need to travel to training events.

I think the problem with the training is the training days aren't local for the staff and there might only be one training day and not all the nurses can go on that one day. (NURS08Acute care nurse).

Opportunities for learning and development were also often negatively impacted by the financial resources available in their respective organisations.

...the problem is that a lot of the training is quite expensive so the nursing homes are not subscribing to it. I mean some of these training days can cost $£ 1200$ for the day. (NURS10 Nursing home nurse)

Barriers to training and practice development resulted in some staff having received no training in dementia care including in pain management.

I haven't had any training with regards to dementia so it's just something that I'm maybe learning from colleagues. (NURS20 - Acute care nurse).

This article is protected by copyright. All rights reserved. 
Whole-group perspectives on interactive learning and practice development

All respondents believed that access to ongoing professional development was critical in empowering staff to effectively and safely manage pain and provide a good standard of holistic care to people dying with advanced dementia. When asked to describe their preferences for training approach, the large majority believed that mentoring and/or shadowing experienced nurses constituted an ideal approach to training. Senior and less experienced nurses believed that 'leading by example' and 'learning by example' were methods most likely to encourage and promote professional and practice development for nurses.

I'm saying to them think about it yourself: if co-codamol isn't strong enough, what would be your next pain relief that you would use? If someone's on this [analgesic] now, how much morphine is this? And if I had to change it, what would I do next? And the staff find that approach is very helpful. (NURSO5 - Hospice nurse)

Participants emphasised that training and practice development should be an ongoing process and required a needs-based approach with input from nursing staff.

You would have to do a needs assessment around the staff and it should be a continual thing not a one-off. But I think staff need to sit down together and start off deciding what their needs are and then they can grow from there. (NURS24 - Nursing Home Nurse)

All nurses reported training in pharmacology was required; some reflected on the dichotomy of holding a position with legal and professional responsibility for administering a large number of medications to vulnerable patients daily without full understanding of what they were providing.

I think nurses are very guilty of sometimes handing out all these medicines and, you know, we hand them out because they're prescribed by the GP but do we really know, you know, do we know the action of these drugs? Do we, you know, are we sure that they're not going interact with any of the other drugs that they have? (NURSO1 - Nursing home nurse)

This article is protected by copyright. All rights reserved. 
All participants in this study expressed that having the appropriate skills and knowledge to competently and confidently manage patients dying with dementia to a 'good death' was of paramount importance.

I want to feel totally equipped to be able to deal with all aspects of their care and never to feel that there was something extra that I could have done...Something that I should have done. (NURSO3 - Nursing home nurse)

\section{DISCUSSION}

This study reported on the experiences of nurses from hospice, acute care and nursing home settings in managing pain for people dying with advanced dementia. Although healthcare policy and clinical guidelines identify symptom management, including pain, as a cornerstone of care at end of life, participant experiences reported in this study illustrated that nurses can find this highly challenging to achieve in practice (van der Steen et al. 2014). This study found that pain management in the final weeks of life was impacted by a number of patient-related, nurse-related and organisational factors. Whilst patient-related factors appeared to be universal across the settings, nurse-related and organisational factors varied between care settings, differentially impacting on nurses' experiences of pain management.

\section{Challenges administering analgesia}

Administration of analgesia was a challenge for all nurses in this study due to patient refusal and/or limited routes of administration. Most believed that patients' severe cognitive impairment and loss of communication inhibited their recognition of analgesia as such and their understanding of its need, prompting refusal. Many nurses were empathetic towards patients' perspectives but felt restricted in their approaches to encouraging compliance in the absence of the nurse-patient dialogue. Difficulties in nurse-patient communication in dementia are well recognised and methods

This article is protected by copyright. All rights reserved. 
to improve this have been well-researched; however, our findings suggest that many of these strategies may remain in the literature and fail to translate into clinical practice (Finke et al. 2008, Weitzel et al. 2011). Patients' physical decline (dysphagia, low body musculature etc.) and/or altered states of consciousness (drowsiness, excessive sleep etc.) limited routes by which analgesia could be administered. Oral, intravenous and subcutaneous administration were considered problematic and perceived to present a high risk of injury, pain and distress to dying patients. Most participants preferred the use of suppositories and transdermal patches, considering them to be low risk and less invasive. Our findings did not elucidate whether difficulties with administration resulted in noncompliance. There has been surprisingly little investigation into the challenges of medication administration in dementia, despite the serious implications of non-compliance for patient outcomes; this area warrants further investigation (Passmore et al. 2010).

The nurse-physician relationship

In this study, nurse-physician relationships appeared to be differentially impacted by care setting. Whilst hospice nurses unanimously reported good working relationships with physicians, acute care and nursing home nurses reported mixed experiences. Positive relationships were characterised by nurses' perceptions that their contribution towards patient care was valued, that they were working in collaborative partnership with physicians and where there was mutual professional respect. Difficult nurse-physician relationships were reported where nurses described themselves as working in parallel with physicians, where participants perceived physicians to be reluctant to assist with complex cases, and/or where pain was inadequately managed. Highly experienced nurses described instances where nurse-physician relationships were negatively impacted by poor communication skills and inadequate reporting among nursing staff, sometimes resulting in inappropriate patient treatment.

This article is protected by copyright. All rights reserved. 
The setting-specific differences in nurse-physician relationships reported here may, in part, reflect the palliative focus of the hospice setting, its ethos, the relative stability and continuity of staff and availability of additional organisational resources. Staff turnover in acute care and nursing home settings may inhibit the establishment and development of close working relationships between nursing and medical staff, particularly in the nursing home context where physicians are based in external surgeries (Tjia et al. 2009). Nurse-physician communication and relationships have been studied extensively and positive relationships have been reported to result in higher job satisfaction for nurses and physicians, sharing of disciplinary knowledge and improved patient outcomes (Prescott \& Bowen 1985, Keenan et al. 1998, Manojlovich 2010). Difficult relationships have resulted in poor job satisfaction, feelings of professional isolation, and errors in patient assessment and management (Donchin et al. 1995, Manojlovich 2010). Clarity in inter-professional working is essential in healthcare and is critical in patient populations unable to effectively communicate their needs; however, these relationships are complex and often impacted by professional boundaries, personal perceptions and organisational cultures.

\section{Interactive learning and development}

Hospice nurses were satisfied with the quantity and quality of opportunities for professional development. Acute care and nursing home nurses; however, experienced significant barriers to accessing training and practice development due to financial, travel and time constraints. Some nurses received no training in dementia; this is a significant concern given the complexities of these patients, their need for tailored care, the prevalence of dementia in these settings and the substantial evidence reporting poor outcomes for pain assessment and management in dementia as a result of inadequately trained staff (Brunier et al. 1995, Closs 1996, Kovach et al. 2000, Weiner \& Rudy 2002, Auret \& Schug 2005, Plaisance \& Logan 2006, Barry et al. 2012, Ghandehari et al. 2013).

This article is protected by copyright. All rights reserved. 
Most respondents believed that learning through case-based discussion and/or mentoring by senior nurses were most likely to stimulate practice development and change. These opportunities needed to be ongoing and developed in consideration of nurses' needs. Participants emphasised that pharmacological training was required, with some expressing concern regarding their lack of understanding of the regimens they administered. This is a key area of practice development given the available evidence regarding inadequate pharmacology knowledge among nursing staff and medication administration errors, omissions and adverse events (McBride-Henry \& Foureur 2006, Dilles et al. 2011).

These findings provide new insight into the experiences of nurses across three care settings in which patients dying with advanced dementia commonly end their lives and the gap between healthcare policy and clinical recommendations for pain management at end of life. Nurses' experiences revealed a number of barriers to pain management at end of life some of which corroborate those reported in Brörson et al. 2014. In addition, our findings highlight areas across and between settings in which nurses are under-supported and may be inadequately equipped to meet standards expected by policy makers.

\section{Limitations}

The nature of the self-selecting sample may have encouraged participation from nurses with an interest in research and those who felt comfortable describing experiences that included accounts of low confidence or competence, or which provided critical accounts of nursing staff and/or care organisations. Nursing home staff comprised $50 \%$ of the total sample. However, within whole-group analyses, nursing home nurses' experiences did not differ substantially from those of acute care and hospice nurses, and in other cases, their experiences reflected those of acute care nurses suggesting that the core themes emerging are not substantially biased to the nursing home context. It is

This article is protected by copyright. All rights reserved. 
acknowledged that acute care nurses were recruited from care of the elderly units linked to teaching hospitals and are likely to display greater awareness of pain in dementia than acute care nurses working in other wards. The findings reported here represent the commonalities of experience and perspectives of this participant sample, drawn from three different care settings and are likely to be reflective of nurses working with the same patient population in the same contexts of care (Mays \& Pope 1995).

\section{CONCLUSIONS}

This study provides a comprehensive exploration of nurses' experiences of pain management for people with advanced dementia in their final month of life. The findings indicate that whilst nurses' beliefs about pain management accord with policy and clinical recommendations for pain management in the final weeks of life, nurses face many challenges in its achievement in practice. The inequality of training and development opportunities for hospice, nursing home and acute care nurses is a concern, given that the rates of referral to hospice and palliative care for people with dementia are consistently lower than those for people with cancer and other comorbid conditions. Dementia care literature has experienced significant expansion in recent years resulting in many empirically supported recommendations for appropriate, holistic, person-centred care for this patient population which often rely on the availability of appropriately equipped, well-trained staff who are confident and competent to provide this care. It is imperative that nurses are adequately supported and equipped with the appropriate knowledge and skills to efficiently manage the needs of what is widely recognised as a complex patient population.

This article is protected by copyright. All rights reserved. 


\section{RELEVANCE TO CLINICAL PRACTICE}

People dying with advanced dementia have complex care requirements including pain and symptom management; however, in order for nurses to meet standards of care expected of them, nurses require adequate and appropriate support from healthcare providers. The current study indicates that acute care and nursing home nurses experience challenges in managing pain for people with advanced dementia in the final month, and are at risk of being undertrained and under-resourced to meet these challenges. Nurses across all healthcare settings in this study self-reported a critical lack of understanding of pharmacology which carries serious implications for patient safety. These findings have been used to develop and pilot an interactive learning and practice development intervention appropriate for all nurses working in dementia, aimed at providing opportunities for sharing knowledge and skills, ongoing professional development and participation in a collaborative approach to patient care. Future work should examine other methods of interactive learning and ways to improve access to practice development.

\section{REFERENCES}

Ahmad S. \& O'Mahony M.S. (2005) Where older people die: a retrospective population-based study. QJM 98(12), 865-870.

Alzheimer's Society (2007) Dementia UK 2007. Retrieved from https://www.alzheimers.org.uk/site/scripts/download_info.php?downloadID=1 on 7 April 2016.

This article is protected by copyright. All rights reserved. 
Auret K. \& Schug S. (2005) Underutilisation of opioids in elderly patients with chronic pain. Drugs \& Aging 22(8), 641-654.

Barry H., Parsons C., Passmore P., Hughes C.M. (2012) An exploration of nursing home managers' knowledge of and attitudes towards the management of pain in residents with dementia. International Journal of Geriatric Psychiatry 27(12), 1258-1266. doi: 10.1002/gps.3770.

Bell M.L. (1997) Postoperative pain management for the cognitively impaired older adult. Seminars in Perioperative Nursing 6(1), 37-41.

Braun V. \& Clarke V. (2006) Using thematic analysis in psychology. Qualitative Research in Psychology 3(2), 77-101.

Brorson H., Plymoth H., Ormon K., Bolmsio I. (2014) Pain relief at the end of life: nurses' experiences regarding end of life pain relief in patients with dementia. Pain Management Nursing 15(1), 315-323. doi: 10.1016/j.pmn.2012.10.005.

Brunier G., Carson G., \& Harrison D.E. (1995) What do nurses know and believe about patients with pain? Results of a hospital survey. Journal of Pain and Symptom Management 10(6), 436-445.

This article is protected by copyright. All rights reserved. 
Cipher D.J. \& Clifford P.A. (2004) Dementia, pain, depression, behavioral disturbances, and ADLs:

Toward a comprehensive conceptualization of quality of life in long-term care. International Journal of Geriatric Psychiatry 19(8), 741-748.

Closs S.J. (1996) Pain and elderly patients: A survey of nurses' knowledge and experiences. Journal of Advanced Nursing 23(2), 237-242.

Cornali C., Franzoni S., Gatti S., Trabucchi M. (2006) Diagnosis of chronic pain caused by osteoarthritis and prescription of analgesics in patients with cognitive impairment. JAMA 7(1), 1-5.

Department of Health. (2009) Living well with dementia: a National Dementia Strategy. Retrieved from https://www.gov.uk/government/publications/living-well-with-dementia-a-national-dementiastrategy on 15 November 2015.

Dilles T., Elseviers M.M., Van Rompaey B., Van Bortel L.M., Stichele R.R. (2011) Barriers for nurses to safe medication management in nursing homes. Journal of Nursing Scholarship 43(2), 171-80. doi: 10.1111/j.1547-5069.2011.01386.x.

Donchin Y., Gopher D., Olin M., Badihi Y., Biesky M., Sprung C.L., Pizoy R., Cotey S. (1995) A look into the nature and causes of human errors in the intensive care unit. Critical Care Medicine 23(3), 294300.

This article is protected by copyright. All rights reserved. 
Finke E.H., Light J., Kitko L. (2008) A systematic review of the effectiveness of nurse communication with patients with complex communication needs with a focus on the use of augmentative and alternative communication. Journal of Clinical Nursing 17(16), 2102-2015. doi: 10.1111/j.13652702.2008.02373.x.

Ghandehari O.O., Hadjistavropoulos T., Williams J., Thorpe L., Alfano D.P., Dal Bello-Haas V., Malloy D.C., Martin R.R., Rahaman O., Zwakhalen S.M., Carleton R.N., Hunter P.V. \& Lix L.M. (2013) A controlled investigation of continuing pain education for long-term care staff. Pain Research and Management 18(1), 11-18.

Hadjistavropoulos T., Voyer P., Sharpe D., Verreault R. \& Aubin M. (2007) Assessing Pain in Dementia Patients with Comorbid Delirium and/or Depression. Pain Management Nursing 9(2), 48-54. doi: 10.1016/j.pmn.2007.12.004.

Hendriks S.A., Smalbrugge M., Galindo-Garre F., Hertogh C.M. \& van der Steen J.T. (2015) From Admission to Death: prevalence and course of pain, agitation, and shortness of breath, and treatment of these symptoms in nursing home residents with dementia. JAMA 16(6), 475-481.

Horgas A. \& Tsai P-F. (1998) Analgesic drug prescription and use in cognitively impaired nursing home residents. Nursing Research 47(4), 235-242.

This article is protected by copyright. All rights reserved. 
Houttekier D., Cohen J., Bilsen J., Addington-Hall J., Onwuteaka-Philipsen B.D. \& Deliens L. (2010) Place of Death of Older Persons with Dementia. A Study in Five European Countries. Journal of the American Geriatrics Society 58(4), 751-756.

Kaasalainen S., Coker E., Dolovich L., Papaionnou A., Hadjistavropoulous T., Emili A., Ploeg J. (2007) Pain management decision making among long-term care physicians and nurses. Western Journal of Nursing Research 29(5), 561-580.

Kaasalainen S., Middleton J., Knezacek S., Hartley T., Stewart N., Ife C. \& Robinson L. (1998) Pain \& cognitive status in the institutionalized elderly: perceptions \& interventions. Journal of Gerontological Nursing 24(8), 24-31.

Keenan G.M., Cooke R. \& Hillis S.L. (1998) Norms and nurse management of conflicts: keys to understanding nurse-physician collaboration. Research in Nursing and Health 21(1), 59-72.

Klapwijk M.S., Caljouw M.A.A., Van Soest-Poortvliet M.C., van der Steen J.T. \& Achterberg W.P. (2014) Symptoms and treatment when death is expected in dementia patients in long-term care facilities. BMC Geriatrics 14:99. doi: 10.1186/1471-2318-14-99.

Kovach C.R., Griffie J., Muchka S., Noonan P.E., Weissman D.E. (2000) Nurses' perceptions of pain assessment and treatment in the cognitively impaired elderly. It's not a guessing game. Clinical Nurse Specialist 14(5), 215-220.

This article is protected by copyright. All rights reserved. 
Manojlovich M. (2010) Nurse/physician communication through a sense-making lens: shifting the paradigm to improve patient safety. Medical Care 48(11), 941-946. doi:

10.1097/MLR.0b013e3181eb31bd.

Mays N. \& Pope C. (1995) Rigour and qualitative research. British Medical Journal 8(6997), 109-112.

McBride-Henry K. \& Foureur M. (2006) Medication administration errors: understanding the issues. Australian Journal of Advanced Nursing 23(3), 33-41.

Mitchell S.L., Teno J.M., Kiely D.K., Shaffer M.L., Jones R.N., Prigerson H.G., Volicer L., Givens J.L. \& Hamel M.B. (2009) The clinical course of advanced dementia. New England Journal of Medicine 361, 1529-1538. doi: 10.1056/NEJMoa0902234.

Monroe T.B., Carter M.A., Feldt K.S., Dietrich M.S. \& Cowan R.L. (2013) Pain and hospice care in nursing home residents with dementia and terminal cancer. Geriatrics Gerontology International 13(4), 1018-1025. doi: 10.1111/ggi.12049.

Morrison R.S. \& Siu A.L. (2000) A comparison of pain and its treatment in advanced dementia and cognitively intact patients with hip fracture. Journal of Pain and Symptom Management 19(4), 240248.

This article is protected by copyright. All rights reserved. 
Nygaard H.A. \& Jarland M. (2005) Are nursing home patients with dementia diagnosis at increased risk for inadequate pain treatment? International Journal of Geriatric Psychiatry 20(8), 730-737.

Passmore P., Wilson D., McGuiness B., Todd S. (2010) Recognition and management of pain in dementia. Geriatric Medicine 41, 499-507.

Plaisance L. \& Logan C. (2006) Nursing students' knowledge and attitudes regarding pain. Pain Management Nursing 7(4), 167-75.

Prescott P.A. \& Bowen S.A. (1985) Physician-nurse relationships. Annals of Internal Medicine 103(1), 127-133.

Prince M.J., Wu F., Guo Y., Gutierrez Robledo L.M., O'Donnell M., Sullivan R., Yusuf S. (2015) The burden of disease in older people and implications for health policy and practice. Lancet 385(9967), 549-562. doi: 10.1016/S0140-6736(14)61347-7.

Rabins P.V. \& Black B.S. (2007) Measuring quality of life in dementia: purposes, goals, challenges and progress. International Psychogeriatrics 19(3), 401-407.

This article is protected by copyright. All rights reserved. 
Reynolds K.S., Hanson L.C., DeVellis R.F., Henderson M. \& Steinhauser K.E. (2008) Disparities in pain management between cognitively intact and cognitively impaired nursing home residents. Journal of Pain and Symptom Management 35(4), 388-396. doi: 10.1016/j.jpainsymman.2008.01.001.

Rolfe G. (2006) Validity, trustworthiness and rigour: quality and the idea of qualitative research. Journal of Advanced Nursing 53(3), 304-10.

Tjia J., Mazor K.M., Field T., Meterko V., Spenard A., Gurwitz J.H. (2009) Nurse-physician communication in the long-term care setting: perceived barriers and impact on patient safety. Journal of Patient Safety 5(3), 145-152. doi: 10.1097/PTS.0b013e3181b53f9b.

van der Steen J.T., Radbruch L., Hertogh C.M., de Boer M.E., Hughes J.C., Larkin P., Francke A.L., Junger S., Gove D., Firth P., Koopmans R.T., Volicer L., European Association for Palliative Care (EAPC). (2014) White paper defining optimal palliative care in older people with dementia: A Delphi study and recommendations from the European Association for Palliative Care. Palliative Medicine 28(3), 197-209. doi: 10.1177/0269216313493685.

Weiner D.K., \& Rudy T.E. (2002) Attitudinal barriers to effective treatment of persistent pain in nursing home residents. Journal of the American Geriatrics Society 50(12), 2035-2040.

Weitzel T., Robinson S., Mercer S., Berry T., Barnes M., Plunkett D., Vollmer C., Foster T., Friedrich L., Allen L., Holmes J., Kirkbride Geri. Pilot testing an educational intervention to improve

This article is protected by copyright. All rights reserved. 
communication with patients with dementia. Journal for Nurses in Staff Development 27(5), 220-226. doi: 10.1097/NND.0b013e31822e0738

World Health Organisation (2012) World health statistics 2012. Retrieved from http://www.who.int/gho/publications/world_health_statistics/EN_WHS2012_Full.pdf on 7 April 2016.

Zwakhalen S.M.G., Hamers J.P.H., Peijnenburg R.H.A., Berger M.P.F. (2007) Nursing staff knowledge and beliefs about pain in elderly nursing home residents with dementia. Pain Research Management 12(3), 177-184.

This article is protected by copyright. All rights reserved. 
Table 1. Participant characteristics

\section{Gender}

Male

$1(4)$

Female

\section{Care setting (Specialty)}

Nursing homes

$12(50)$

Acute care

$6(25)$

Hospice

Years' experience

$<5$

\section{Additional qualifications}

None

or related field 
Table 2. Core themes and sub-themes identified in within-group and cross-group analysis

$\begin{array}{ll}\text { Core theme } & \text { Sub-theme }\end{array}$

Challenges administering analgesia

The nurse-physician relationship

Interactive learning and practice development

(b) Acute care and nursing home nurses

(c) Whole-group perspectives on interactive learning and development

This article is protected by copyright. All rights reserved. 